"This is a preprint of an article published in New Zealand Journal of Educational Research. The final authenticated version is available online at: https://doi.org/10.1007/s40841-020-00187-9"

\title{
The use of furniture in a student-centred primary school learning environment.
}

\author{
Louise Starkey ${ }^{\mathrm{a} *}$, Victoria Leggett ${ }^{\mathrm{a}}$, Craig Anslow ${ }^{\mathrm{b}}$ and Aniebietabasi \\ Ackley $^{\mathrm{c}}$
}

${ }^{a}$ School of Education, Victoria University of Wellington, New Zealand.

${ }^{b}$ School of Engineering and Computer Science, Victoria University of Wellington, New Zealand.

${ }^{c}$ School of Architecture, Victoria University of Wellington, New Zealand.

*louise.starkey@vuw.ac.nz

\begin{abstract}
Classroom furniture has evolved over time from fixed desks facing the front to maintain order and control to a range of flexible furniture types to encourage student-centred pedagogies. This article reports research that applied a sociomaterial approach to explore how furniture is used in a flexible learning environment. Data were gathered from observations, reflections, student focus group interviews and teacher interviews in one school in New Zealand. In this context it was found that students used furniture for different purposes. Individual student preferences and differences were evident including unconventional use of furniture. The use of furniture was influenced by the teachers, students, environment, furniture design and the curriculum, and mediated by pedagogy and a focus on developing autonomy and environmental competence. The students demonstrated environmental competence, including awareness of the ways that the available furniture can be used for different types of curriculum activities and how environmental and social conditions can affect comfort, collaboration and concentration levels. In classrooms where students move around the space, environmental competence should be deliberately embedded in the teaching programme implicitly and explicitly. In this context, the teachers controlled the environment and the students had restricted autonomy over their use of furniture. The notion of student-centredness in contemporary classroom environments requires further investigation.
\end{abstract}

Keywords: furniture; student-centred; primary school, flexible learning environment, environmental competence

\section{Introduction}

Classroom furniture plays a significant role in the day to day lives of children attending school. Within socio-material theory (Fenwick, Edwards, \& Sawchuk, 2015) furniture can be considered a material aspect of the social environment of the classroom, 
influencing decisions made by students and teachers. The furniture used within classrooms evolves over time and across contexts reflecting resources available, beliefs, and educational policies. Influenced by the OECD, a current trend in the New Zealand context is the introduction of a range of furniture types in open plan or flexible classrooms, also known as modern or innovative learning environments (OECD, 2013; 2015).

In the early 1900s school desks with attached seating were fixed to the floor and having movable desks could be a cause of disorder (Le Garde, 1911). The beliefs about the role of education at the time included developing obedience and self-discipline. It was also a time when information about the world was restricted to written or oral formats which in the schooling context was through textbooks, wall charts and the knowledge of the teacher. Classroom furniture was fixed facing the same direction for order and control (Herman, Van Gorp, Simon, \& Depaepe, 2011) and to enable children to focus on the teacher at the front of the classroom.

The design of school furniture is examined in the literature. It is discussed in terms of specifications for furniture in a context where central agencies order school furniture across a country (for example, Tormey, 1942). Explored in the specifications are health related concerns. This includes furniture that will not harm children by eliminating sharp edges (Hageman, 1935), anthropometric considerations (for example, Panagiotopoulou, Christoulas, Papanckolaou, \& Mandroukas, 2004; Saarni, Nygård, Kaukiainen, \& Rimpelä, 2007) to maximise comfort and focus students on learning (da Silva et al., 2012; Knight \& Noyes, 1999) and the effect of sitting still or moving on health of children (Cardon, De Clercq, De Bourdeaudhuij, \& Breithecker, 2004; Dyson et al., 2010; Garcia et al., 2016). One study has explored the use of school desks as gymnastic equipment in Italian primary schools between 1870 and 1970 (Brunelli \& Meda, 2017). More recently the health effects of using flexible furniture and digital devices has been explored (Binboğa \& Korhan, 2014).

The movement from fixed furniture to movable desks that could be organised in different configurations resulted in studies that explore the pedagogical uses of furniture for group discussion (Berchuck \& Tauss, 1973; O'Hare, 1998) or for classroom management purposes (Stewart, Evans, \& Kaczynski, 1997). The notion of developing students' environmental competence emerged within the context of teachers giving children choice over classroom layout (Sommer, 1977). Environmental competence enables effective use of physical spaces for educational purposes.

More recently flexible learning environments with fewer desks than children and different types of furniture such as bean bags, tables, cushions and sofas have been introduced into schools. In addition, furniture is not allocated to specific students or teachers. This reflects a significant change in beliefs, policies and resources since the start of the 1900s underpinned by societal change such as the access to information broadening from texts to digitised resources and interactive technologies (Starkey, 2012). Rather than a focus on order and control, flexible learning environments are designed with the belief that teachers should focus on the students as individuals and their learning needs (OECD, 2013). While students and teachers have reported they like the comfort and choice of furniture options within flexible learning spaces (Kariippanon, Cliff, Lancaster, Okely, \& Parrish, 2018), the use of classroom furniture in flexible learning environments is currently under researched. Furniture use was 
examined in this context, where a classroom had a range of furniture types and students had choice about which furniture to use.

\section{Socio-material actor network theory}

Actor network theory is a socio-material sensibility derived from complexity theory. It recognises the situatedness of educational processes and the interrelationships between social and material aspects (Fenwick \& Landri, 2012). Socio-material approaches consider both the patterns and unpredictability that makes educational activity possible by recognising the interactions between the 'things' in education such as students, teachers, learning activities and spaces, knowledge representations such as texts, pedagogy, and curriculum content (Sørensen, 2009). Within socio-material research mediators make a difference to the outcomes of interactions between actors while intermediaries do not (Fenwick et al., 2015). This article reports on a study that applied a socio-material approach to explore the research question; how is furniture used within a flexible learning environment in a New Zealand school? The socio-material elements included the curriculum, environment, furniture, teachers and students.

\section{Method}

The research was conducted in one state primary school learning environment in New Zealand. This bounded the study and a focus was placed on the interactions between socio-material elements which may influence furniture use.

\section{The learning environment}

The learning environment was originally three separate cellular classrooms, which had been converted to a flexible open plan learning space through the removal of a large portion of the interior walls to join the spaces and has several pieces of furniture for the students to use and breakout spaces which are converted cloakrooms (Figure 1). Three teachers, two teacher aides and 90 year 5-6 students, age 9-11 were using the 
space moving between the three classrooms.

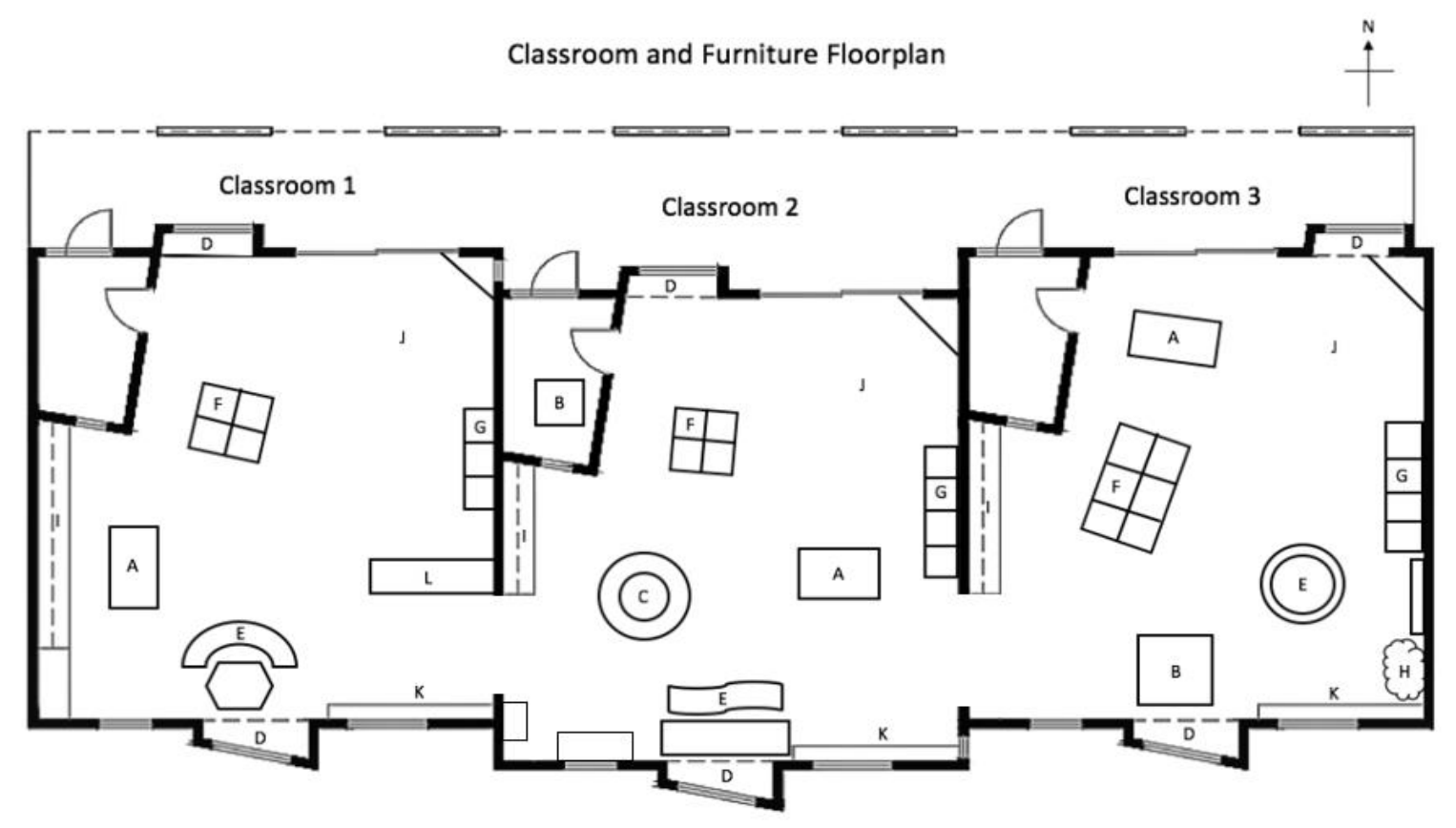

Figure 1. The flexible learning space.

\section{The furniture}

The furniture within the flexible learning space consisted of whiteboard tables (A, B, and C), window seats (D), ottomans Key to furniture type: $\mathrm{A}=$ high whiteboard tables $\mathrm{B}=$ low whiteboard table $\mathrm{C}=$ whiteboard table with seats $\mathrm{D}=$ window seats $\mathrm{E}=$ Ottomans $\mathrm{FG}=$ traditional desks $\mathrm{H}=$ Beanbags (E), traditional desks ( $F$ and $\mathrm{G}$ ) and beanbags

$(\mathrm{H})$, and there were cushions that could be moved around the room. The whiteboard tables were at three heights, one for children standing or sitting on tall stools at (A), one for sitting on the floor (B), and a third in a circular shape at mid-height with cushioned benches surrounding the surface for the students to sit at $(\mathrm{C})$. The traditional desks were positioned in two different formats in each of the classroom, one set in a group, and one positioned in a line along the right-hand wall. In both classrooms 1 and 2, the grouped desks consisted of four individual tables each with a chair, with a line of three tables along the wall in classroom 1 , and a line of four in classroom 2 . In classroom 3 , the grouped desks had six individual tables with a line of four desks along the adjacent wall. Benches with sinks over cupboards (I) and areas with no furniture (J) were available for children to use. Along the south wall are individual tote trays (K) where students stored their personal resources for learning, including digital devices. There was an additional low-sitting table (L) in classroom 1 with six desktop computers that the students have access to.

\section{Participants}

The research had approval from Victoria University of Wellington's Human Ethics 
Committee with approval number: 26850 . The school principal, teachers, students and their parents were invited to consent to participate and identities were kept confidential. The three teachers and 20 out of the 86 students in the learning space participated in the study. Six of these students were purposively selected to participate in a focus group interview. The six students interviewed were chosen with advice from the teachers to represent diverse personalities and learning approaches from the students who had volunteered to participate in the research.

\section{Data gathering}

Data were gathered through observations, 20 student online reflections through google forms, a focus group interview with six purposively selected children and an interview with the three teachers of the space. Multiple data sources enable the examinations of critical socio-material connectivities (Fenwick et al., 2015). The observational data was gathered over five two-hour sessions in a week near the end of the 2018 school year. These sessions aimed to cover different times throughout the day, and included two morning sessions from 9am to 11:30am, a mid-morning session from 11:30am to $1 \mathrm{pm}$ and two afternoon sessions from $2 \mathrm{pm}$ to $3 \mathrm{pm}$. The lessons and activities during these sessions differed but covered content from mathematics to creative projects. The data included written observations describing notable occurrences within the classroom from the students' behaviour to the teachers' instructions to create a detailed snapshot of the factors that may influence furniture use in the learning environment. Maps of the space were annotated to provide a visual overview that connected with the written observations. At the end of that week students completed reflections and interviews were conducted. The reflections asked the students about their furniture preference for when they need to concentrate, collaborate or when they are feeling tired, grumpy or whakamā (a psycho-social Māori construct used in New Zealand that doesn't have a direct western translation. It can include being withdrawn, shamed or self-doubting).

\section{Data analysis}

Data were analysed using a thematic analysis through Nvivo software, firstly analysis focused on location and furniture use patterns across the different data sets. Results were then summarised to theorise the significance of patterns (Patton, 1990) by applying a socio-material lens to the data to identify actors and mediators which influenced the observed patterns (Fenwick et al., 2015).

\section{Results}

The three teachers worked collaboratively to construct a timetable and learning activities across each week. Within a timetabled activity each teacher had a different teaching role, one may have been teaching a small group of students, another may have been working with individual students and a third may have been leading a larger group activity. Students either worked independently, with other students, or participated in a teacher-led activity. The scheduled timetable and expectations of what students should be doing are online and displayed on screens in the learning environments. When attending a large group activity, the children had the choice of sitting on the floor, using nearby furniture or bringing cushions to sit on. For small group activities they were with 
the teacher around a table or on the floor. For individual or collaborative learning the children chose where they went and what furniture they used across the available spaces.

The furniture was a key material aspect of interest in this research. The types of furniture included whiteboard tables, ottomans, window seats, desks and chairs and soft furnishings which were used for different purposes by the students and teachers. There was variation between student preferences and use.

\section{Whiteboard tables}

The five whiteboard tables have a surface which allows students and teachers to use them as a temporary thinking space where they can write, draw, and erase ideas. There were three tall rectangular tables at standing height (A) in each of the three classrooms, one circular table with circular padded ottomans (C) in classroom 2, two short rectangular whiteboard tables, one in the breakouts space of classroom 2 and one larger short square table in front of the window seat in classroom 3 (Figure 2).

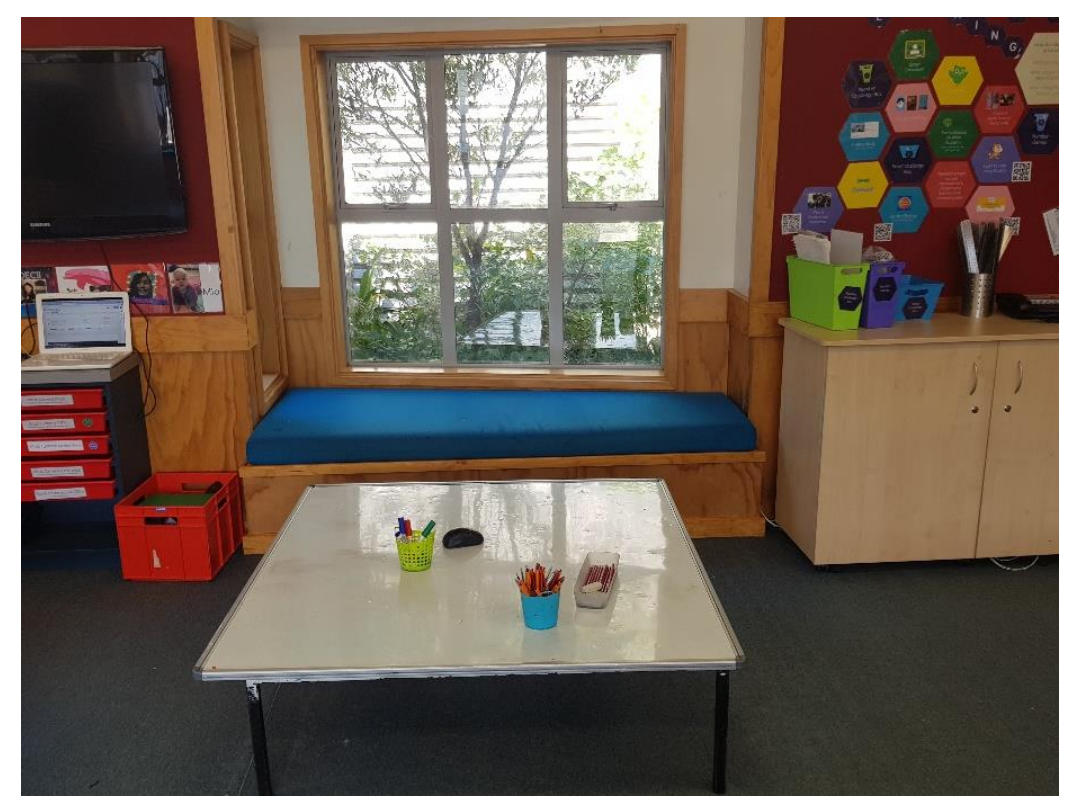

Figure 2. Whiteboard table in front of south facing window seat.

The whiteboard tables were a popular choice of furniture used by the teachers and students. Students seemed to prefer working at the whiteboard tables over other pieces of furniture for both individual learning activities or when collaborating with other students.

The whiteboard tables were used extensively during maths activities. Students noted in their reflections that whiteboard tables helped them; "I am always concentrating when I am doing maths and I like to write down ideas on a whiteboard table". A teacher reported that if a student approached them with a maths problem, they guide them over to a whiteboard table to help them lay out their thinking. This suggests that the teachers encouraged the use of whiteboard tables, particularly for maths. 
A tall whiteboard table was situated close to the makerspace bench where creative projects were centred. This close proximity appeared to influence the choice and use of the table for creative purposes. For example, a student said they used this table for creative purposes "because there are lots of workshops there so you can get ideas", and another "because it's next to the arts station". During an inquiry session, nine girls were observed to have positioned themselves at this table. Five of these students were working on their inquiry projects on the surface of the table, whilst the remaining four were sitting on the floor beneath the table on their devices and engaging with one another.

Students were drawn to collaborate at the whiteboard table for two reasons; to share ideas by writing these on the table and "because it's probably the loudest and me and my buddy can talk louder than in other spaces". Some students reported that they avoided the whiteboard tables as they were aware that they would be distracted by other children at the tables. For example, a student from the focus group explained that they found one particular whiteboard table as "just evil" as they struggled to concentrate there due to the presence of their friends.

\section{Ottomans}

There were three sets of ottomans, one in each of the classrooms. Two of these were positioned next to desks as bench seats for the students to sit on while working at the desks (Figure 3). The third set was positioned in a ring or circle shape with an empty space in the middle. During the observation period, it was noted that these pieces of furniture were used as benches as the layout would suggest and in alternative ways throughout the sessions. For example, the ottomans were used as a desk when students would place their device or book they were working in on the surface of the ottoman and place themselves on the floor next to it. This was not due to a lack of space at the desk alongside the ottomans, as the desk had space for the student to set up their work. One student was observed to sit solely on an ottoman for an entire morning session, holding their device in front of them and using headphones. Another notable use occurred when a student placed the seat length ways against the cluster of desks to use it as a seat at the desk, rather than the usual desk chairs found at the tables. This moving of the ottomans was noted by the teachers who reported that the students often drag them over to their tote tray areas to place their work or project in the tray and engage in creative work. The teachers also noted that the students enjoy walking across the top of the ottomans rather than walking on the floor space alongside it, they discouraged this parkour type behaviour but had seen it occur frequently. 


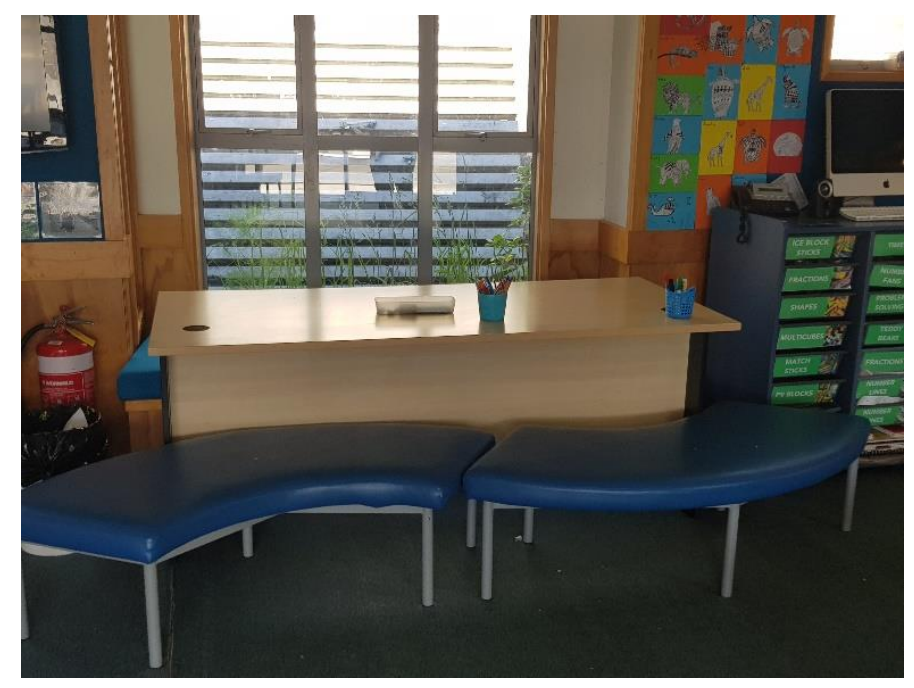

Figure 3. Ottomans in front of a table.

\section{Window seats}

There were two window seats per classroom at each end of the room. The ones by the veranda face north and have sun streaming in much of the day (Figure 4). The others faced south with little direct sun. Each seat was padded with a thick cushion for comfort. The use of these pieces of furniture varied amongst the students. It was observed that the activities that take place on this furniture tend to be quieter individual work, students read a book for a session or used their devices. Similar to the ottomans, students would place their books or devices on the seat itself and then place themselves on the floor next to the seat and work in that fashion, again, noting that there were a large number of traditional desk spaces available for the student to use, as well as the rest of the window seat space being available.

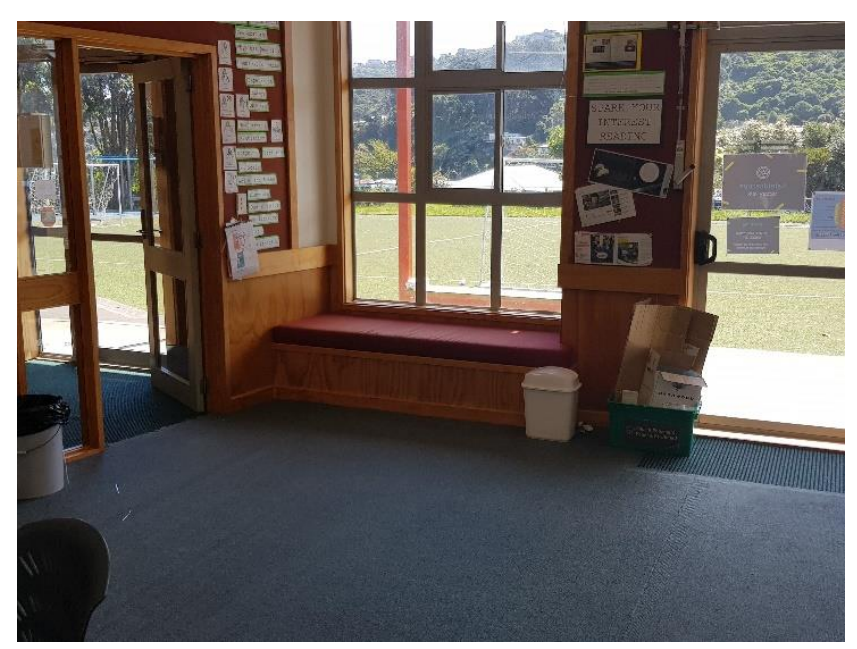

Figure 4. North facing window seat.

Environmental aspects influenced how window seats were used. The sunny north facing window seats were a place for individual work. During the observations there were few occurrences of two students simultaneously working at the window seats. When students did sit together they work independently, rarely communicating 
with each other. A teacher confirmed this, noting that they didn't often see students collaborating in these spaces, rather they seemed to prefer to sit and work quietly. Many students identified the window seats as the places they like to go when they are feeling grumpy, tired, or whakamā, citing reasons such as "I can lie down on it and can lean on the wall. I'm also higher than everyone so it's like a bed", and "It's a comfortable place to sit and helps me relax". However, the southern facing window seats that had the tables next to them seemed to be a place of collaboration, one student chose the window seat as their favourite place to collaborate in their reflection "because it's by a window and also because it's comfy".

The students reported mixed feelings about using the window seats. The environmental conditions and comfort drew students to the space; "I like the window seat because it's pretty warm there and all the sun is on your back". The location of the seats on the periphery of the classroom also influenced their use; "I love the window seats because they're really comfy and you can lie down on them and not be in the middle of the floor". However, the teachers believed that while some students enjoyed huddling into the window seats for the sense of comfort, some also used the peripheral location as an opportunity to be off task while online.

The environmental conditions were attributed to the use of window seats for creative work and for concentration. In their reflections, students listed a window seat space the place they like to go to when being creative "because it is nice to sit on and there is lots of light" and "because when I'm doing creative writing nobody can look at my work and distract me." Some students felt the window seats were a good place to concentrate, "Because it's a nice quiet space there and there's a window seat as well and I don't really get distracted there". However, other students noted it to be one of the spaces where they find themselves easily distracted. One student said that they often find their friends in those spaces and can find that very distracting, and another student noted that because those spaces can get very hot and bright in the summer, this can also cause distraction.

\section{Desks and chairs}

In each classroom, there were two groups of standard school desks and chairs with a total of 25 desks available for 90 students. One group in each room is positioned facing each other (Figure 5) and the others are placed in a line facing a wall. In observations these pieces of furniture were not used as often as the whiteboard tables, window seats or flooring areas. The exception was the group of desks in classroom 3. 


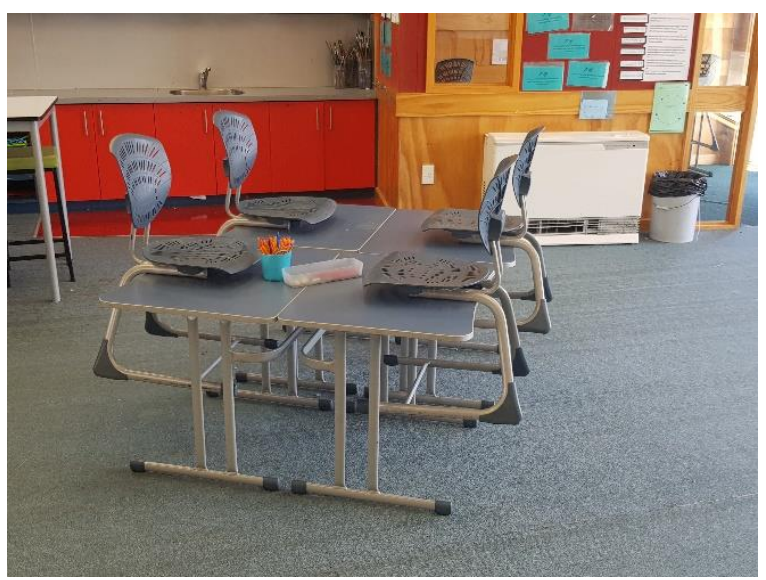

Figure 5. Group of desks.

The desks positioned along the wall, like the window seats, were identified as places for concentration and independent activities. Within the reflections, one student explained that they could concentrate when sitting at these desks "because most times whenever I sit there, my friends aren't there". Being places of independence, the desks against the wall of the classroom were a place where students said they went if they felt tired, grumpy, or whakamā, "because it's a place where I can relax", and "no one can really see you there". From observations, it was noted that even when each of the desks were occupied, the students did not openly engage with one another "I don't really know why but I kinda go there and no matter whether other people are there or if I'm just on my own... I go here because it's usually nice and quiet and fun to do work".

Both desk configurations were identified as furniture used for creative projects for conflicting reasons; "It is tucked away and has enough space" or "because it is really open". This reflects different student preferences. The desks facing each other were a popular choice for collaboration, with students explaining that there is more space for them to spread out their work or "lots of friends can work there".

The location of the desks in proximity to other areas of the classroom used for specific activities influenced their use. One student identified the grouped desks in each of the classrooms as the furniture they would use if needing to concentrate, reasoning that "because they're by the workshop I can get some stuff and also because they're just normal tables ... it's easy to work there". Other students explained that they sit at a group of desks closest to a workshop as it helps them to concentrate on the task at hand. For example, one student liked the grouped desks in classroom 3 "because it's closest to the spelling workshop and when I need to finish off the tiny bit of spelling that I have because spelling is usually in classroom 3". Another student suggested that "because there's people around you and they're mostly all doing different things" enabled them to concentrate.

Students chose which set of desks they work at depending on the nature of the task at hand, proximity, and their preferences. For example, a student outlined that with priority work that they feel stressed about they will choose to work at the desks facing the wall "because it's all in a row so there's nothing really to distract you", or they 
chose to work at the grouped desks if they have work to do that they are not feeling stressed about, citing also that it is a bit less quiet in comparison to the other desks in other sections. They also noted that if they have work that they are required to collaborate on with a partner, they will choose to work at the grouped desks in classroom 3 because "you can easily see each other" and they are "really good if you want to collaborate with someone". This student also mentioned that if they need to concentrate on maths activities specifically, they will use the grouped desks in classroom 2 "because it's large and not many people actually go here so I can put my stuff here". One student noted the group of desks in classroom 1 to be where they become easily distracted since they often find their friends there. Others listed the section $\mathrm{G}$ desks as places to concentrate "Because it is usually really quiet" and "Because it is close to the lesson".

\section{Soft Furnishings}

Soft furnishings in this learning environment included bean bags, lilypad cushions and a soft fur-like rug in classroom 3. These items of furniture are often sought out by students who are looking to relax or have quiet time. During observation sessions, some students would gravitate towards the bean bag with their devices. The bean bag was in a corner of the classroom and the area was named the 'book nook' (Figure 6). These students often became distracted throughout the duration of the session as they would be seated there with a friend or engaging in something off task on their devices. During a reading session after lunch, one student moved a bean bag and a few cushions to the window seat in classroom 3 for comfort while listening to a story.

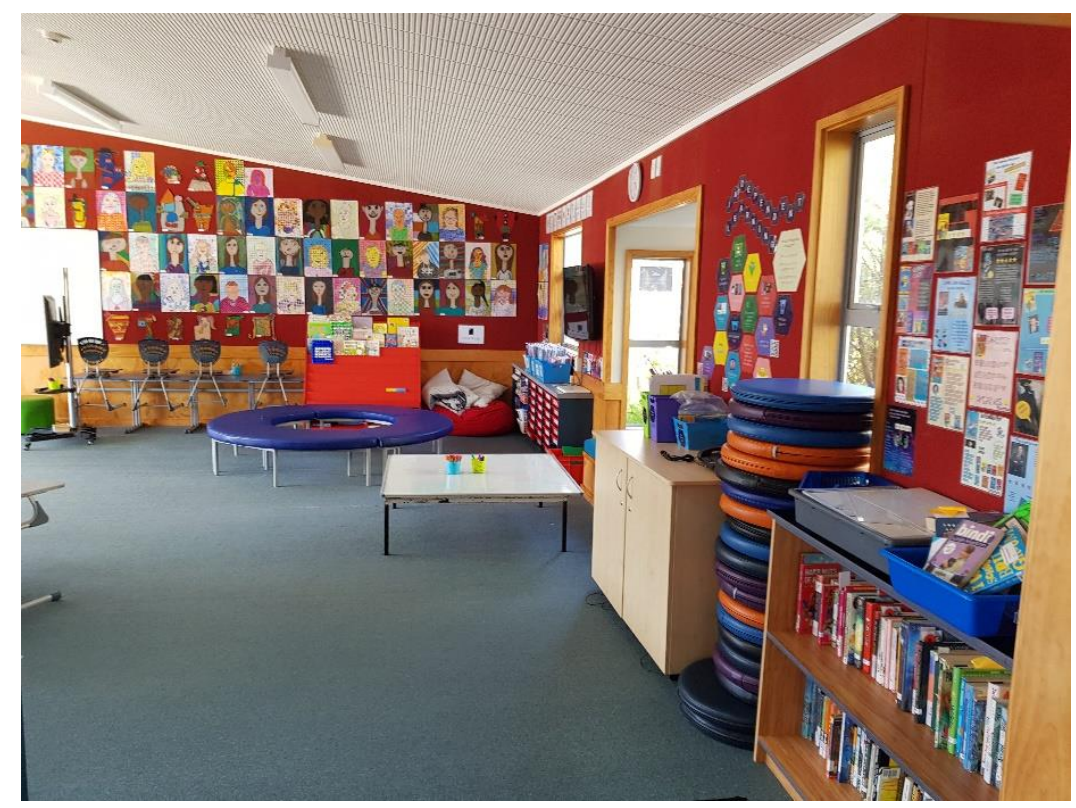

Figure 6. Beanbag in the corner 'the book nook' and the lilypads on the right, round ottomans and desks facing the wall on the left.

In the reflections, students identified the book nook as the place they prefer to go when they are feeling tired, grumpy, or whakamā, "because bean bags are nice and relaxing", and "because it is in small place and you can sit by yourself". In the student focus group, when asked where the students' favourite place in the classroom was, one 
answered with the book nook area "because it has bean bags", another noted that specifically in winter, they like to sit in corner areas, especially the book nook because "that's where the bean bags are and it encloses you in so you can just lie there and feel the warmth". The teachers explained that they endeavoured to give each breakout space a different feel, hence the space in classroom 3 being called "The Cosy Cove", with a soft rug and some cushions which allows the students to have a space to relax.

Lily pads are flat, circular cushions that were available for the students to use as they like. A pile of around fifteen of these cushions were in classroom 3. These were an aspect of the classroom's range of soft furnishings and have been observed to be used in different ways by the students that demonstrated student autonomy. During observations, it was noted that one student chose to sit on top of the pile of lily pad cushions to engage in some independent reading. During a reading session, students took the cushions over to their mat areas to lie down and listen to the stories. When a group of workshop students were told that they could shift elsewhere in the classroom, one student took a pile of five or six lily pads to sit at a low whiteboard table and do their work.

\section{Furniture use}

Furniture was used in different ways by the children in this study. There was a general trend for students to prefer furniture at the periphery of the classroom for independent study, such as the window seats and the desks that faced a wall and the whiteboard desks for collaborative learning tasks, particularly in mathematics.

Furniture was not always used in conventional ways. The window seats and the ottomans were sometimes used as tables or students lay on these while working. Children sometimes sat under desks to work. One child was observed doing a balancing act on a chair while listening to a teacher read from a book. She managed to bend over backwards with her head touching the ground while being absorbed in the teaching that was occurring at the same time. This use of furniture may not have been tolerated at the start of the 1900s when schooling had a focus on obedience and self-discipline, however, it does reflect the current focus in education on developing the child as an individual with autonomy and collaborative skills. Across the data sources it was evident that the children in the study were aware of the choices they were making, and most chose options that favoured successful learning rather than social distraction, but as might be expected, not all children all the time and the teachers were aware of this.

\section{Socio-material influences on furniture use}

The students in the learning environment used furniture in different ways and for different reasons. The choices they made about furniture use were influenced by five broad socio-material actors; the teachers, the students, environmental factors, the learning activities (the curriculum), and furniture design (Figure 7). The culture of the classroom, including the focus on student autonomy, pedagogy and developing student environmental competence were mediators. 


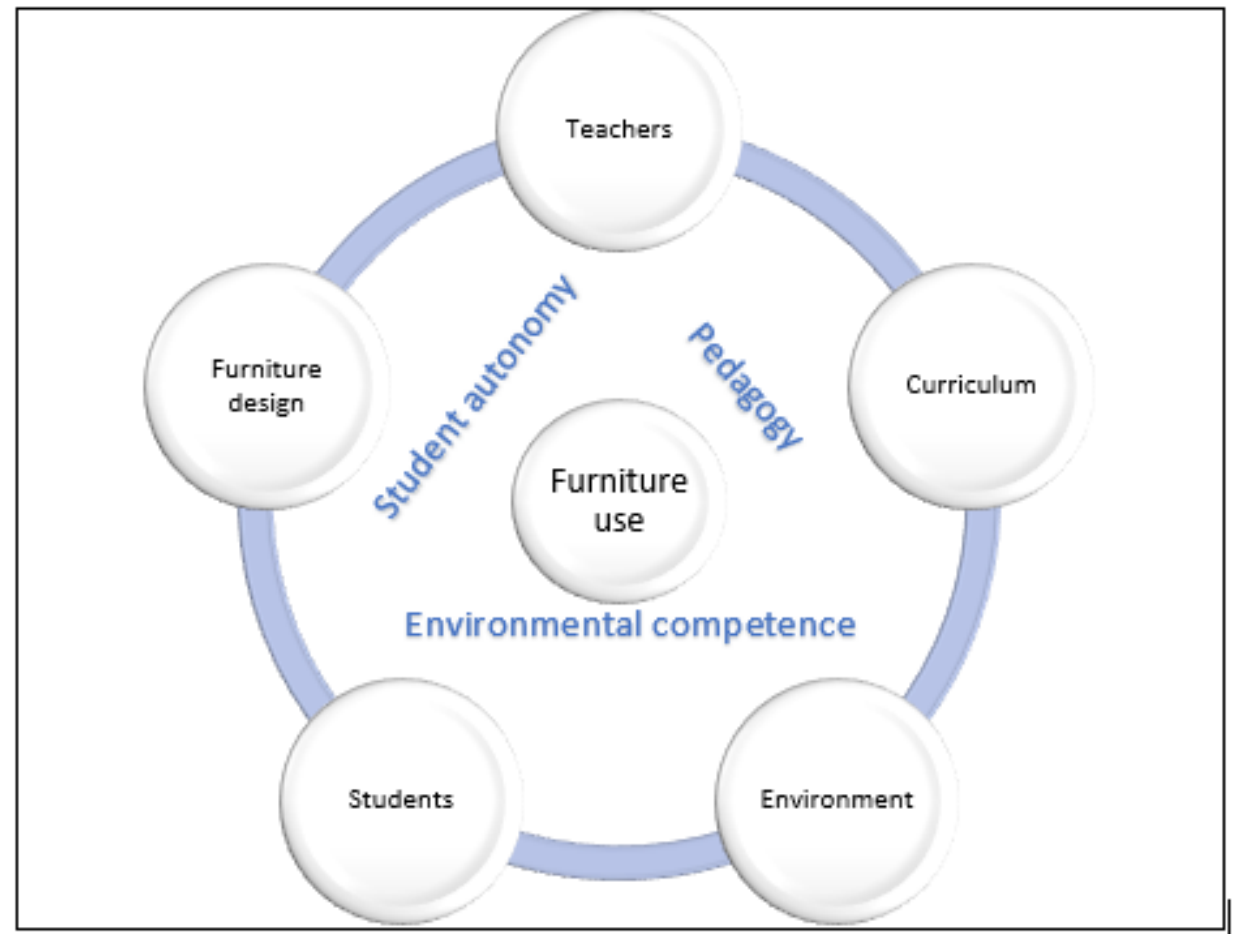

Figure 7. Socio-material elements influencing furniture use in a flexible learning environment.

\section{Teachers}

The teachers set up the learning environments. Each classroom had a different focus, with classroom 1 being a noisier, creative space, classroom 3 being a quieter space with books, and classroom 2 providing a mix. The teachers deliberately positioned the tables and chairs across the space to influence the use of furniture. For example, tables were strategically placed in the south side of the classroom to limit children running through the three spaces and using furniture to practice parkour. They also placed six computers on a low table in classroom 1 as they had observed that they were not being used when they were on traditional height school desks. They positioned only two chairs at the tall tables to encourage students to stand while doing their work.

The teachers directed the daily classroom curriculum schedule and controlled the environment. They made considered pedagogical decisions with direct and indirect guidance on use of furniture to develop children's autonomy in making decisions about where they did their learning and the furniture they used. For example, one teacher was observed to take a student to a whiteboard table to coach them on a maths problem. By modelling and encouraging the use of the whiteboard tables, the teachers influenced the way students use the space, and this was reflected in the children's own use of the furniture. Direct guidance to develop the children's environmental competence included reminding students to avoid sitting with friends if this was a distraction. 


\section{Environment}

Environmental factors influenced the choices that children made about furniture use. Sitting in the window seats where there was sunshine on their backs helped some to concentrate and others found this distracting. Furniture placed at the periphery of the classroom, facing a wall or in corners encouraged individual study whereas whiteboard tables or desks facing each other encouraged collaboration (Figure 8). Furthermore, environmental factors such as light, temperature, and general ambience of certain spaces also interact with choices made regarding the student use of furniture. When the students were feeling tired, grumpy or whakamā they liked to be alone in spaces that were comfortable, particularly in the warmth of the sun or enveloped within a beanbag. The children were aware of the reasons for the choices they were making, demonstrating environmental competence.

Figure 8 . Furniture or places identified by students for different purposes.

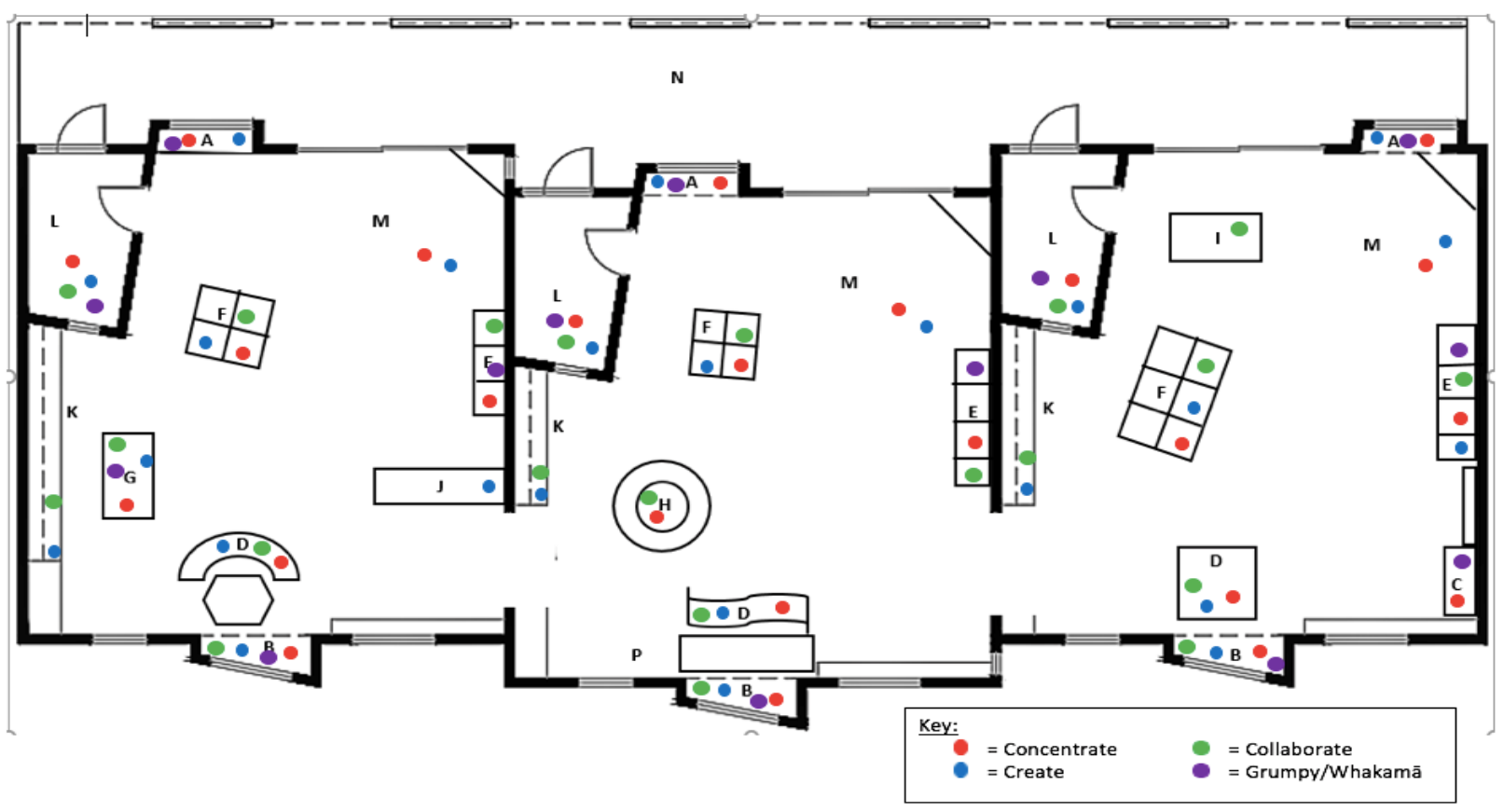
$A=$ sunny window seats
$\mathrm{B}=$ window seats, not sunny.
$\mathrm{C}=$ Beanbags
$\mathrm{D}=$ whiteboard table with seats
$\mathrm{EF}=$ traditional desks
$\mathrm{G} \mathrm{I}=$ high whiteboard tables
$\mathrm{H}=$ Ottomans
$\mathrm{J}=$ low desks with fixed computers
$\mathrm{K}=$ Makerspace area
$\mathrm{L}=$ Breakout room
$\mathrm{M}=$ floor or 'mat' area

Within the environment, proximity to other material aspects influenced student choice of furniture use. Access to resources such as fixed computers, books and creative resources influenced where students chose to work and therefore the furniture that was used. Some students said that they chose to sit on furniture in places where they were 
likely to get help from the teachers, and alternatively others chose a place where they were less visible to avoid teacher conversations.

\section{Curriculum}

The curriculum influenced pedagogical approaches and furniture choices. The data from both the student reflections and the student focus group revealed the capacity of the students to make informed decisions regarding the best place to engage in activities and tasks ranging from maths and spelling to more creative projects reflecting environmental competence. Developing students' self-management skills, a key competency within the New Zealand Curriculum (2007), was a strong influence within the studied environment.

Where students preferred to go for specific curriculum tasks is mapped onto the spaces in Figure 9. Students were directed to workshop activities on the floor in the mat areas (M), whereas independent curriculum tasks took place anywhere the students chose. Some students liked to sit close to where a teacher was teaching a particular curriculum aspect to a small group of students so that they could listen. Others identified how curriculum interacted with environmental choices; moving away from noise or potential distractions was a priority when choosing the best place to go to concentrate on maths and spelling activities. These observations reflect the interaction between social and material aspects of the environment when making decisions about furniture use.

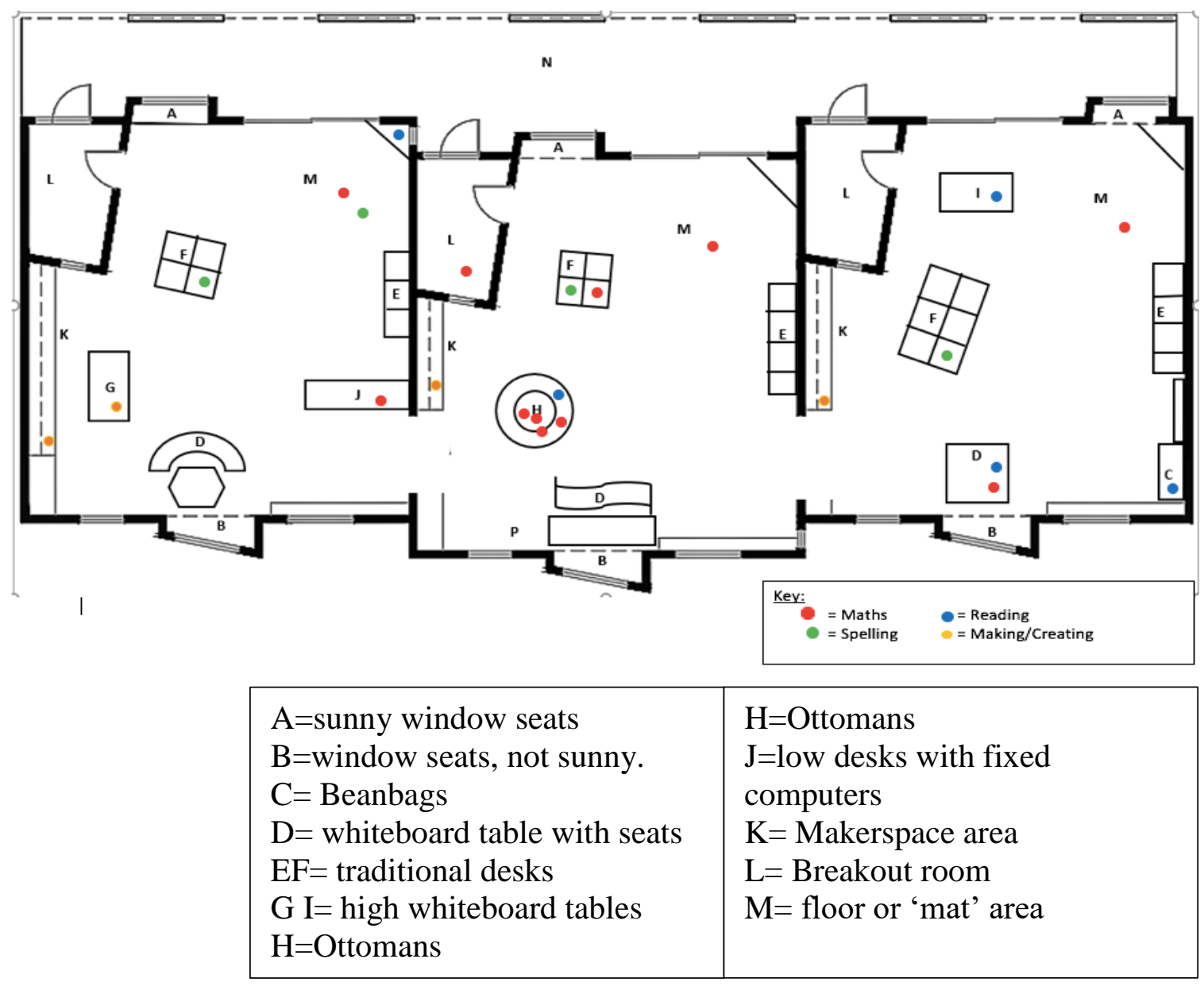


Figure 9. Classroom layout mapping out use of furniture connected to specific curriculum activities.

\section{Students}

The students in the class influenced their use of furniture. While we identified general trends of furniture choice, there were differences in the preferences expressed by individual students. The choices made were influenced by the mood of the student and where their peers were sitting. If a student was feeling tired, grumpy or whakamā they made different choices to when they were feeling excited about something. Where friends were sitting would influence students to sit next to them to collaborate or talk, or to avoid that area to minimise distractions. They were able to do this because of the culture of the classroom, their perceived autonomy and environmental competence.

\section{Discussion}

The introduction of a learning environment with flexible furniture choices has emerged out of the belief that education should be student-centred rather than occur in a context of teacher-centred order and control (OECD, 2013). Teacher-centred or student-centred education can be on a continuum, they are not clearly defined and contain different dimensions (Starkey, 2019). In the few studies that focus on the use of furniture in the classroom, earlier papers reflected a focus on standardised furniture that supported a context of order, discipline and control (for example, Le Garde, 1911).

Biesta (2017) warns that student-centred education can disempower the role of the teacher in the classroom context which can negatively affect the academic outcomes for students. A study by Deed and Lesko (2015) in a secondary context found students more directive than teachers in both the use of the open space and the furniture within it through reorganising and shifting pieces around to suit their learning activities. This contrasts with this study where teachers gave the students restricted autonomy within the learning environment in their use of furniture. The teachers set the curriculum, organised the layout of the environment, set expectations and guided the students towards how to use the space and develop environmental competence. The students had some choice where they worked and could move the soft furnishings. Therefore, the teachers controlled the environment, and the role of the teacher was an important aspect of the classroom. While teachers controlled the environment 100 years ago, the purpose and context of the control has changed.

The students in this study made thoughtful decisions about their use of furniture. They demonstrated environmental awareness with the choices they made, matching their decisions to the schedule of activities set by the teachers, and their personal aims, preferences and mood, although like in previous learning environment research (for example, Charteris, Smardon, \& Nelson, 2017), these aims were occasionally to be social or not be noticed by the teachers. The teachers provided the structure, control and guidance in the learning environment which included encouraging self-management. This is not self-discipline to obey, rather the development of self-management skills to focus on learning within an environment of choice and distractions. 
The students' attitudes toward their learning environment reflects a degree of environmental competence advocated by Sommer (1977). The students clearly articulated environmental, pedagogical and social reasons for their choice of furniture. They were aware of how temperature, sunshine, learning tasks, mood, proximity and their peers' choices influenced their decisions about furniture and where they positioned themselves. Environmental competence in this context included awareness of autonomy, preferences, the environmental and social conditions influencing their learning and how to align furniture choices with the tasks they were undertaking. Environmental competence was deliberately embedded in the teaching, both explicitly and implicitly.

The use of furniture was influenced by socio-material elements including the teacher, the students, the curriculum being taught, the furniture design and the environment. Lei (2010) posits that uncomfortable and ill-designed classroom settings can have a profound impact on students' sense of comfort and overall experience of the room. The students in this study appeared to have a sense of comfort and satisfaction within the environment. Daniels, Tse, Stables, and Cox (2018) argue that the design of a classroom should align with the intended pedagogical approach and is successful when the practices within the space match the vision. This is a design view of classrooms. In reality, teachers adapt their practice to the context of their teaching, resources available and their beliefs (Charteris et al., 2017; Kim, Kim, Lee, Spector, \& DeMeester, 2013). The observed use of the environment aligns with a teacher-controlled student-centred pedagogical approach.

Previous studies are dominated by a focus on health-related concerns associated ergonomics of furniture design, the anthropometrics or fit of the furniture to the size of children and postural outcomes from sitting at desks. This study did not directly explore health related aspects of furniture use, but it is worth noting that the children's unconventional use may raise postural concerns as they use laptops or tablets for their learning (Binboğa \& Korhan, 2014), lie down to read, use seats as tables or collaborate under a table. However, this may be negated by their freedom to move in the environment and while using furniture, which has been found to have positive health effects (Cardon et al., 2004; Dyson et al., 2010). Further studies are needed in this area which could be used to further inform teacher and students' environmental competence.

This research has implications for classroom teaching and further research. Teachers need environmental competence to make informed decisions about their use of the classroom and how they teach students to make choices about furniture use. Further research is needed to explore furniture use in different contemporary classroom contexts to develop a rich literature about different aspects of environmental competence. This includes investigating different socio-material elements, pedagogical approaches, health implications associated with ergonomics, and levels of student autonomy and teacher control.

\section{Conclusion}

The type of furniture available in classrooms and research exploring furniture use has changed as beliefs and framing about the purpose of schooling has evolved. The application of a socio-material lens enabled us to identify five categories of influences 
on the way that the students used the furniture; the teachers, students, furniture, curriculum and environment. The use of furniture was mediated through the pedagogical practices and the focus in the classroom on developing environmental competence and student autonomy. The teachers directly and indirectly controlled the environment, limiting the extent of student-centredness and autonomy. The use of furniture reflects a classroom culture with a focus on developing student autonomy rather than order and obedience, however, the teachers, as in the past, had control over the environment.

In classrooms where students move around the space, environmental competence should be deliberately embedded in the teaching programme both explicitly and implicitly. Environmental competence includes awareness of autonomy, the ways that the available furniture can be used for different types of curriculum activities and how environmental and social conditions can affect comfort, collaboration and concentration levels.

\section{References}

Berchuck, I., \& Tauss, V. (1973). Opening classroom: guiding the transition from traditional to open classroom. Elementary School Journal, 74, 78-83. doi:10.1086/460803

Binboğa, E., \& Korhan, O.(2014). Posture, Musculoskeletal Activities, and Possible Musculoskeletal Discomfort Among Children Using Laptops or Tablet Computers for Educational Purposes: A Literature Review. Journal of Science Education \& Technology, 23(5), 605-616. doi:10.1007/s10956-014-9505-9

Brunelli, M., \& Meda, J. (2017). Gymnastics between school desks. History of Education Review, 46(2), 178-193. d

Cardon, G., De Clercq, D., De Bourdeaudhuij, I., \& Breithecker, D. (2004). Sitting habits in elementary schoolchildren: a traditional versus a "Moving school". Patient education and counseling, 54(2), 133-142.

Charteris, J., Smardon, D., \& Nelson, E. (2017). Innovative learning environments and new materialism: A conjunctural analysis of pedagogic spaces. Educational Philosophy \& Theory, 49(8), 808-821. doi:10.1080/00131857.2017.1298035

da Silva, L. B., Eliza, J., Coutinho, A. S., Soares, E. V. G., de Lourdes Silva dos Santos, R., Jacobs, K., \& Soares, M. M. (2012). Analysis on the relationship between the school furniture and the work surface lighting and the body posture of public Middle School students from João Pessoa, Paraíba, Brazil. Work, 41, 5540-5542.

Deed, C., \& Lesko, T. (2015). 'Unwalling'the classroom: Teacher reaction and adaptation. $18(2), 217-231$.

Dyson, S. M., Abuateya, H., Atkin, K., Culley, L., Dyson, S. E., \& Rowley, D. (2010). Reported school experiences of young people living with sickle cell disorder in England. British Educational Research Journal, 36(1), 125. 
Fenwick, T., Edwards, R., \& Sawchuk, P. (2015). Emerging approaches to educational research: Tracing the socio-material: Routledge.

Fenwick, T., \& Landri, P. (2012). Materialities, textures and pedagogies: socio-material assemblages in education. Pedagogy, Culture \& Society, 20(1), 1-7.

Garcia, J. J., Huang, T., Trowbridge, M., Weltman, A., Sirard, J., Garcia, J. M., . . . Sirard, J. R. (2016). Comparison of the Effects of Stable and Dynamic Furniture on Physical Activity and Learning in Children. Journal of Primary Prevention, 37(6), 555-560. doi:10.1007/s10935-016-0451-6

Hageman, H. A. (1935). Streamlined Schoolhouses Wanted by Newton Planner. Journal of Education, 118(15), 425-425. Retrieved from

Herman, F., Van Gorp, A., Simon, F., \& Depaepe, M. (2011). The school desk: from concept to object. History of Education, 40(1), 97.

Kariippanon, K. E., Cliff, D. P., Lancaster, S. L., Okely, A. D., \& Parrish, A.-M. (2018). Perceived interplay between flexible learning spaces and teaching, learning and student wellbeing. Learning Environments Research, 21(3), 301-320. doi:http://dx.doi.org/10.1007/s10984-017-9254-9

Kim, C., Kim, M. K., Lee, C., Spector, J. M., \& DeMeester, K. (2013). Teacher beliefs and technology integration. Teaching and Teacher Education, 29, 76-85.

Knight, G., \& Noyes, J. (1999). Children's behaviour and the design of school furniture. Ergonomics, 42(5), 747-760. doi:10.1080/001401399185423

Le Garde, E. (1911). Proper school furniture for the child. Journal of Education, 74(1), 11-13.

O'Hare, M. (1998). Classroom design for discussion-based teaching. Journal of Policy Analysis \& Management, 17(4), 706-720. doi:10.1002/(SICI)15206688(199823)17:4<706::AID-PAM7>3.0.CO;2-O

OECD. (2013). Innovative Learning Environments. Paris: OECD.

OECD. (2015). Schooling redesigned: Towards innovative learning systems. Paris: OECD.

Panagiotopoulou, G., Christoulas, K., Papanckolaou, A., \& Mandroukas, K. (2004). Classroom furniture dimensions and anthropometric measures in primary school. Applied Ergonomics, 35(2), 121.

Saarni, L., Nygård, C. H., Kaukiainen, A., \& Rimpelä, A. (2007). Are the desks and chairs at school appropriate? Ergonomics, 50(10), 1561-1570. doi:10.1080/00140130701587368

Sommer, R. (1977). Classroom layout. Journal of theory into practice. 16(3), 174-175. 
Sørensen, E. (2009). The Materiality of Learning: Technology and Knowledge in Educational Practice. Cambridge: Cambridge University Press.

Starkey, L. (2012). Teaching and learning in the digital age. Routledge.

Starkey, L. (2019). Three dimensions of student-centred education: a framework for policy and practice. Critical Studies in Education, 60(3), 375-390.

Stewart, S. C., Evans, W. H., \& Kaczynski, D. J. (1997). Setting the stage for success: assessing the instructional environment. Preventing School Failure, 41, 53-56. doi:10.1080/10459889709603268

Tormey, T. J. (1942). Furniture and equipment for school buildings. Review of educational research, 12, 203-210. 